UCRL-JC-131660

:

PREPRINT

\title{
Element-Specific Magnetometry with Linear Dichroism in Photoemission
}

\author{
F.O. Schumann \\ R.F. Willis \\ K.W. Goodman \\ J.G. Tobin
}

\begin{abstract}
This paper was prepared for submittal to Journal of Electron Spectroscopy and Related Phenomena and

12th Conference on Vacuum Ultra Violet Radiation Science San Francisco, CA August 3-7, 1998
\end{abstract}

July 1998

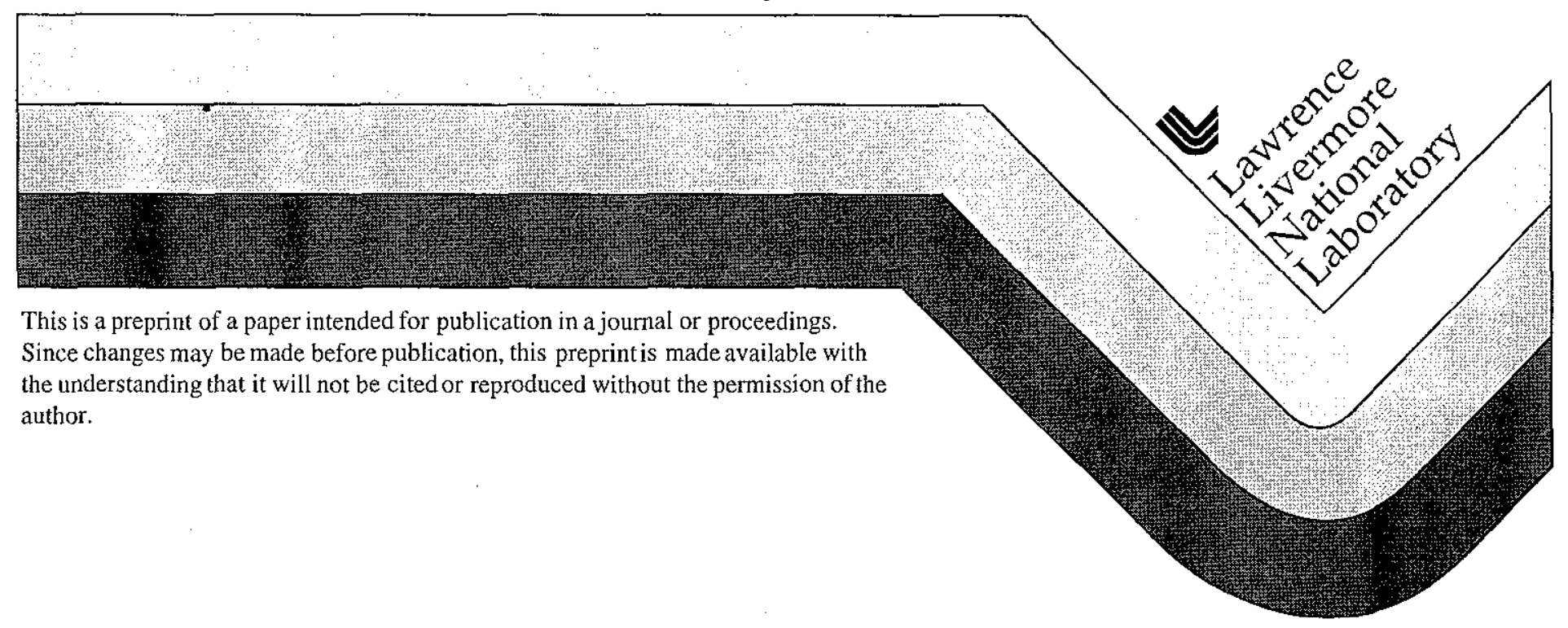




\section{DISCLAIMER}

This document was prepared as an account of work sponsored by an agency of the United States Government. Neither the United States Government nor the University of California nor any of their employees, makes any warranty, express or implied, or assumes any legal liability or responsibility for the accuracy, completeness, or usefulness of any information, apparatus, product, or process disclosed, or represents that its use would not infringe privately owned rights. Reference herein to any specific commercial product, process, or service by trade name, trademark, manufacturer, or otherwise, does not necessarily constitute or imply its endorsement, recommendation, or favoring by the United States Government or the University of California. The views and opinions of authors expressed herein do not necessarily state or reflect those of the United States Government or the University of Califomia, and shall not be used for advertising or product endorsement purposes. 
Element-specific magnetometry with linear dichroism in photoemisision

F.O Schumann and R.F. Willis

The Pennsylvania State University, Department of Physics, University Park, PA 16802

K.W. Goodman and J.G. Tobin

Department of Chemistry and Material Science, Lawrence Livermore National Laboratory, Livermore, CA 94550

\section{Abstract}

In this paper, we investigate the magnetic linear dichroism in the core-level photoemission spectra of the binary alloys $\mathrm{Co}_{x} \mathrm{Ni}_{1-x}$ and $\mathrm{Fe}_{x} \mathrm{Ni}_{1-}$ $x / C u(100)$.These epitaxial films have fcc structures, but very different magnetic behavior.We show that the magnetic linear dichroism in $\mathrm{x}$-ray photoemission (XMLD) signal tracks the magnetization in these alloys. Comâprison with recent SQUID data provides a quantitative check and endorses the view that XMLD monitors the element-specific magnetometry.

PACS: 75.70.Ak, 75.50.Bb, 79.60.Dp

$$
\begin{aligned}
& \text { SUSM TTREO TO: J. EL. SPECT. REL. PHEN. }
\end{aligned}
$$

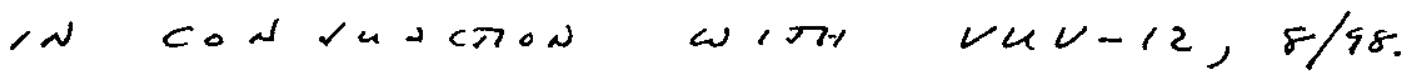


Magnetic dichroism in absorption and core-level photoemission has emerged as new tool for probing magnetic properties. Core-level spectroscopy is inherently element-specific and offers the possibility to investigate element-specific magnetic properties. Specifically it has been shown that changes in the magnetization can be tracked elementspecifically $[1,2]$.

However, a lack of consensus on what constitutes the spectroscopic lineshapes questions the applicability of this method. In this letter, we present results which show conclusively that the dichroism of the integrated sums of the spectral lineshape track the changing magnetization in these alloys. Specifically, we report on the concentration dependence of the magnetic dichroism for fcc $\mathrm{Co}_{x} \mathrm{Ni}_{1-x}$ and $\mathrm{Fe}_{x} \mathrm{Ni}_{1-x}$ ultrathin alloy films of the $3 p$ core levels in photoemission with linearly polarized light (XMLD). In the case of $\mathrm{Co}_{x} \mathrm{Ni}_{1-x}$ alloys we have compared the dichroism obtained with circular and linearly polarized light, and observed essentially the same trends in behavior using both methods[3].

We have choosen fcc $\mathrm{Co}_{x} \mathrm{Ni}_{1-x}$ and $\mathrm{Fe}_{x} \mathrm{Ni}_{1-x}$ binary alloys because of their very different behavior in the bulk. $\mathrm{Co}_{x} \mathrm{Ni}_{1-x}$ is structurally and magnetically well-behaved in particular the magnetic moment varies linearly as a function of concentration[4]. This is in sharp contrast to fcc $\mathrm{Fe}_{\mathrm{x}} \mathrm{Ni}$ 1-x which displays a magnetic instability at $\sim 65 \% \mathrm{Fe}$ content[5]. An extended regime of fcc stabilility is possible via epitaxy on $\mathrm{Cu}(100)$ [6-8]. If XMLD is indeed a sensitive probe of the element-specific magnetization, we should expect very different behavior for this latter alloy. This has been observed and will be discussed in the following. 
Growth and structural aspects of $\mathrm{Co}_{x} \mathrm{Ni}_{1-x}$ and $\mathrm{Fe}_{x} \mathrm{Ni}{ }_{1-x} / \mathrm{Cu}(100)$ have been thoroughly studied and we found for both systems good epitaxial growth in the fcc structure[7, 8]. The dichroism experiments were performed at the SpectroMicroscopy Facility on Beamline 7 at the Advanced Light Source, Berkeley[9]. For photoemission of the $3 p$ core levels we utilized $190 \mathrm{eV}$ photons (p-polarized) and collected electrons in normal emission with an angular resolution of $2^{\circ}$. The angle of incidence of the photon beam was $60^{\circ}$ with respect to the surface normal and the magnetization was in the 'transverse' geometry[8]. A field pulse from a coil near the sample magnetized the sample along the $\{001\}$ direction.

First we display the concentration dependent $3 p$ magnetic dichroism asymmetry for $\sim 6 \mathrm{ML} \mathrm{Co}_{x} \mathrm{Ni}_{1-\mathrm{x}} / \mathrm{Cu}(100)$ in fig.1 [10]. For the $\mathrm{Co} 3 p$ level we find a constant asymmetry of $\sim 10 \%$ which agrees with previous work by Kuch et al.[11], who investigated $\mathrm{Co} / \mathrm{Cu}(100)$. For the $\mathrm{Ni} 3 p$ level we observe a small value of $\sim 2 \%$. The results of the XMLD measurement suggest that the magnetic states of the $\mathrm{Co}$ and $\mathrm{Ni}$ atoms are not changing, since their asymmetry remains constant as the stochiometry is changed. From the bulk we also know that the moments are concentration independent[4]. This might be regarded as evidence that the XMLD asymmetry is tracking a quantity closely related to the element-specific magnetic moment[2].

In fig. 2 we show the magnetic dichroism asymmetry for the $\mathrm{Fe}$ and $\mathrm{Ni} 3 \mathrm{p}$ levels. We notice a high asymmetry for the $\mathrm{Fe} 3 \mathrm{p}$ level at low $\mathrm{Fe}$ concentrations which is strongly reduced at high $\mathrm{Fe}$ concentrations. As explained previously [8]we can identify three regimes (I-III) on the basis of the variation of the atomic volume and the Fe magnetic asymmetry[8]. 
Clearly the concentration dependence is now distinctively different in the $\mathrm{Fe}_{\mathrm{x}} \mathrm{Ni}_{1-\mathrm{x}}$ alloy.

We want to discuss now to what extent XMLD can be used for elemental magnetometry of alloys. We were encouraged to pursue this aspect of our work by the results of Sirotti et al. on Fe bulk samples[2]. They compared the low-temperature dependence of the $\mathrm{Fe} 3 \mathrm{p}$ linear dichroism and asymmetry in the the spin-polarization of secondary electrons. The latter is now very well established to be proportional to the magnetization[12]. Sirotti et al. observed that both techniques gave identical results and they concluded that the XMLD asymmetry is indeed proportional to the overall magnetization.

As shown in fig.1, the element-specific magnetic properties of $\mathrm{Co}$ and $\mathrm{Ni}$ in $\mathrm{Co}_{x} \mathrm{Ni}_{1-x}$ remain constant. From these data, we find that the average dichroism asymmetry for Co and $\mathrm{Ni}$ is $9.8 \%$ and $2 \%$, respectively.

We can replot the data of fig. 1 by 'calibrating' the average asymmetries in the following way: (i) $9.8 \%$ asymmetry equals $1.7 \mu_{\mathrm{B}}$ for Co and (ii) $2 \%$ asymmetry equals $0.6 \mu_{\mathrm{B}}$ for $\mathrm{Ni}$.

These are the known magnetic moments for bulk Co and Ni[4, 13]. Now we are able to calculate the average moment as a function of concentration for each data point. First we convert the dichroism asymmetry for $\mathrm{Co}$ and $\mathrm{Ni}$ into an element-specific moment. Secondly we calculate the average moment using the following stochiometric equation:

$$
\mu=x \cdot \mu_{C o / F e}(x)+(1-x) \cdot \mu_{N i}(x)
$$


If we replace the actual data points with the averaged dichroism asymmetry for $\mathrm{Co}$ and $\mathrm{Ni}$, the solid line results, plotted in fig. 3. The error bars reflect the uncertainties of the original data in fig.1.

We can repeat this procedure for $\mathrm{Fe}_{\mathrm{x}} \mathrm{Ni1}$-x alloys, for which we use the following " calibration": (i) $8.5 \%$ asymmetry equals $2.5 \mu_{\mathrm{B}}$ for $\mathrm{Fe}$ and (ii) $2 \%$ asymmetry equals $0.6 \mu_{\mathrm{B}}$ for Ni. In fig. 2 we have shown that the phase diagram of $\mathrm{Fe}_{\mathrm{x}} \mathrm{Ni}_{1-\mathrm{x}}$ alloys can be divided into 3 regimes. We concluded that $\mathrm{Fe}$ is in a high-spin (HS) state for concentrations up to $\sim 65 \%$. Following the work of Abrikosov et al. we associate this state with an atomic magnetic moment of $2.5 \mu_{\mathrm{B}}$; for $\mathrm{Ni}$ we have used again the bulk value[14]. Again we can calculate the average moment using equation (1). The solid line in fig.4 is the result if we replace the actual data points by the fitted curve in fig.2. Clearly in order to endorse XMLD as an element-specific magnetometer we need a comparison to results using absolute magnetometer. Recently Freeland et al. provided results to this effect on ultrathin $\mathrm{Fe}_{\mathrm{x}} \mathrm{Ni}_{1-\mathrm{x}}$ alloys[15]. They investigated $4 \mathrm{ML}$ thick $\mathrm{Fe}_{x} \mathrm{Ni}_{1-x}$ multilayers grown mainly on a Cu(111) substrate. Using SQUID magnetometry they have determined absolute values of the average moment. We show their results together with our reploted data from figs. 3 and 4 , in fig.5. We have also included also a data point for $6 \mathrm{ML} \mathrm{Fe} / \mathrm{Cu}(100)$ from a previous publication of the same group[16]. This clearly shows an almost linear increase for $\mathrm{Fe}$ concentrations up to $\sim 65 \%$. Extraplotes to a value of $\sim 3 \mathrm{mb}$ in its fcc $\mathrm{Fe}$ is in a HS state. Further evidence that the Fe moment stays constant in a HS state up to $65 \% \mathrm{Fe}$ has been provided by Mössbauer spectroscopy [15].

This work confirms our conclusions based on the high value of the $\mathrm{Fe}$ asymmetry up to $\sim 65 \% \mathrm{Fe}$ content as discussed previously[8]. 
Going beyond $65 \%$ Fe content Freeland et al. observe a strong reduction of the magnetic moment towards smaller values. For pure Fe they find a magnetic moment of $\sim 1 \mu \mathrm{B}$. In this Fe-rich regime, their data show a considerable scatter of values, presumably due to different amounts of strain.This is particularly true for the (100) oriented thin films. These show a consistently smaller value of the moment than those in the (111) orientation.

The apparent discrepancy between the experimental data points and our work (full line) in fig. 5 can be explained as follows. The difference between the 2 data points from samples with the (100) orientation is due to the thickness. Increasing the thickness obviously reduces the average moment due to the relief of volumetric strain, which is consistent with the Mössbauer experiments on $\mathrm{Fe} / \mathrm{Cu}(100)$ [17]. Thickness dependent magnetic and structural properties are known to exist in the thickness regime 4-7 ML [17-20]. This is also true for $\mathrm{Fe}_{\mathrm{x}} \mathrm{Ni}_{1-\mathrm{x}} / \mathrm{Cu}(100)$ alloy films as previously reported [8]. We suspect that the $\mathrm{Fe}_{\mathrm{x}} \mathrm{Ni}_{1-\mathrm{x}}(111)$ films investigated by Freeland et al. have not the same atomic volume as our films for $\mathrm{Fe}$ concentrations larger than $65 \%$. Either the films in the (111) direction have not fully relaxed or there is real difference in the volume instability. As it turns out there is evidence for the latter. The structure of $\mathrm{Fe} / \mathrm{Cu}(111)$ has been carefully determined by means of LEED I-V [21]. In accord with earlier reports [22] it is found that for thicknesses up to $5 \mathrm{ML}$ a fcc phase exists and we derive an atomic volume of $11.68 \AA^{3}$ for $5 \mathrm{ML}$. This value is almost exactly in between 11.4 and $12.1 \AA^{3}$ which are representative for 2 different magnetic phases in the case of $\mathrm{Fe} / \mathrm{Cu}(100)[20]$. We have essentially derived the same values via an extrapolation [8]. Following the work of Keavney et 
al. we associate an atomic volume of $11.4 \AA^{3}$ with an average Fe moment of $0.3 \mu \mathrm{B}$. On the other hand an average moment of $\sim 2 \mu_{\mathrm{B}}$ can has been observed for the HS state[16, 17]. Making the reasonable assumption that the moment is a linear function of the atomic volume[16] we determine an average moment of $\sim 1 \mu \mathrm{B}$ for fcc $\mathrm{Fe} / \mathrm{Cu}(111)$. This is in good agreement with the results of Freeland et al.[15].

It is also important to note that Tian et al. do not observe extra spots in the fcc phase contrary to the observation for fcc $\mathrm{Fe} / \mathrm{Cu}(100)[18,20,23]$. Obviously the structural instabilities and therefore magnetic states do not manifest themselves as clearly for pure $\mathrm{Fe} / \mathrm{Cu}(111)$ as compared to $\mathrm{Fe} / \mathrm{Cu}(100)$. Our work and the results of Freeland et al. agree that for up to $\sim 65 \% \mathrm{Fe}$ content $\mathrm{Fe}$ is in a HS state. Beyond this concentration the behavior of the atomic volume for $\mathrm{Fe}_{\mathrm{X}} \mathrm{Ni}_{1-\mathrm{x}}$ in the (100) and (111) orientation is different.

So far we have discussed our results in terms of ground state properties. However our measurements have been performed at temperatures in the range $250-300 \mathrm{~K}$. We will show that any effect of temperature is rather minimal and not significant in the present context. The variation of the magnetization for bulk $\mathrm{Ni}$ is given in reduced temperature units $T / T_{c}$ in Kittel[13]. We see for example that for $\mathrm{T} / \mathrm{T}_{\mathrm{C}}=0.7$ the magnetization is still 80 $\%$ of $\mathrm{M}(0 \mathrm{~K})$. For example we investigated $\sim 6 \mathrm{ML}$ thick $\mathrm{Ni} / \mathrm{Cu}(100)$ with XMLD and we know that $\mathrm{T}_{\mathrm{C}} \sim 400 \mathrm{~K}$ [24]. This means that $300 \mathrm{~K}$ is equal to 0.75 in reduced units. Consequently the error associated with the measurement at 'high' temperatures is much smaller than the error bar for the Ni XMLD asymmetry, see fig.4. It is the latter which results in the rather large error bar of our average moment plot in figs. 3 and 4. Alloying $\mathrm{Ni}$ 
with Co pushes the $T_{c}(d)$ dependence quickly up[7]. We find for $6 \mathrm{ML}$ $\mathrm{Co} 10 \mathrm{Nig}$ (hat $300 \mathrm{~K}$ is equivalent to $\sim 0.65$ in reduced units. Now the magnetization has only decreased by $\sim 10 \%$. This trend of a decreasing deviation of the magnetization continues if the Co content is increased. Therefore we conclude that the error due to thermal exciations can be neglected and is at all times smaller than the error bar of the average moment, see fig.3. We can now apply the same reasoning for $\mathrm{Fe}_{\mathrm{x}} \mathrm{Ni}_{1-\mathrm{x}}$ alloy films. For concentrations up to $\sim 65 \%$ Fe the thermal excitations account for only $\sim 10 \%$ decrease in $\mathrm{M}(0 \mathrm{~K})$.

For concentrations beyond $65 \%$ Fe we have to assume a larger deviation. As shown in a previous publication[7] $\mathrm{Fe}_{75} \mathrm{Ni}_{25} / \mathrm{Cu}(100)$ alloys show only weak thickness dependence of $T_{c}$ in the thickness interval $4-10$ ML. The value is around $300 \mathrm{~K}$ which is not much higher than $250 \mathrm{~K}$ which was the temperature during thickness dependent measurements [8]. We now estimate that the magnetization has decreased by $40 \%$. Therefore we should replace the value of $0.3 \mu_{\mathrm{B}}$ for pure Fe with $0.5 \mu_{\mathrm{B}}$. This is still significantly too small when compared with the data of Freeland et al for the (111) orientation. Therefore the remaining differences are mainly due to the different volume instability for $\mathrm{Fe}_{\mathrm{x}} \mathrm{Ni}_{1-\mathrm{x}} / \mathrm{Cu}(111)$.

In summary, we have systematically investigated element-specific magnetic properties with XMLD for two different binary alloys. These results endorse the use of XMLD in photoemission as an element-specific technique for studying ferromagnetism in metastable, binary-alloy, epitaxial films. The difference in the integrated spectral lineshapes when the direction of the magnetization is switched reflects the magnitude of the magnetization. This is clearly reflected in the contrasting behavior of the $\mathrm{Co}_{x} \mathrm{Ni}_{1-x}$ and 
$\mathrm{Fe}_{\mathrm{x}} \mathrm{Ni}_{1-\mathrm{x}}$ alloys with changing stochiometry. The observed behavior of the ferromagnetic response suggests a simple summing of the magnetic moments, depending on the alloy composition. This in turn, further underlines the magnetometry deduced from the XMLD signals.

Funding was provided via NSF grant DMR-95-21126. This work was also performed under the auspices of the U.S. Department of Energy by LLNL under contract No. W-7405-ENG-48. We would like to thank Drs. J. Denlinger, E. Rotenberg and A. Warwick. 


\section{References}

[1] D. Schmitz et al., Phys. Rev. B 54, 15352 (1996)

[2] F. Sirotti, G. Panaccione and G. Rossi, Phys. Rev. B 52, R17063 (1995)

[3] S.Z. Wu et al., J. Vac. Sci. Technol. A 15, 2287 (1997)

[4] M.F. Collins and D.A. Wheeler, Proc. Phys. Soc. 82, 633 (1963)

[5] E.F. Wassermann, J. Mag. Magn. Mat. 100, 346 (1991)

[6] J. Dresselhaus et al., J. Mag. Magn. Mat. 148, 172 (1995)

[7] F.O. Schumann et al., Phys. Rev. B 56, 2668 (1997)

[8] F.O. Schumann et al., Phys. Rev. Lett. 79, 5166 (1997)

[9] J.G. Tobin et al., J. Appl. Phys. 79, 5626 (1996)

[10] The element-specific asymmetry is calculated as the ratio of the difference spectrum over twice the mean peak height. We can not use the expression $\mathrm{I}$ (up)-I(down)/I(up)+I(down) due to the concentration dependence of the $3 p$ peak heights.

[11] W. Kuch et al., Phys. Rev. B 51, 609 (1995)

[12] H.C. Siegmann, J. Phys.: Condens. Matter 4, 8395 (1992)

[13] C. Kittel, Introduction to Solid State Physics. (John Wiley \& Sons, Inc., New York, Chichester, Brisbane, Toronto, Singapore 1991)

[14] I.A. Abrikosov et al., Phys. Rev. B 51, 1058 (1995)

[15] J.W. Freeland, I.L. Grigorov and J.C. Walker, Phys. Rev. B 57, 80 (1998) 
[16] D.J. Keavney et al., Phys. Rev. Lett. 74, 4531 (1995)

[17] R.D. Ellerbrock et al., Phys. Rev. Lett. 74, 3053 (1995)

[18] J. Thomassen et al., Phys. Rev. Lett. 69, 3831 (1992)

[19] M. Zharnikov et al., Phys. Rev. Lett. 76, 4620 (1996)

[20] S. Müller et al., Phys. Rev. Lett. 74, 765 (1995)

[21] D. Tian, F. Jona and P.M. Marcus, Phys. Rev. B 45, 11216 (1992)

[22] W. Kümmerle and U. Gradmann, Solid State Comms. 24, 33 (1977)

[23] J. Thomassen, B. Feldmann and M. Wuttig, Surf.Sci. 264, 406 (1992)

[24] F. Huang et al., Phys. Rev. B 49, 3962 (1994) 
Figure caption

Fig.1: Concentration dependence of the Co (points) and Ni (squares) $3 p$ asymmetry for $6 \mathrm{ML}$ thick films at $300 \mathrm{~K}$.

Fig.2: Concentration dependence of the $\mathrm{Fe} 3 \mathrm{p}$ and $\mathrm{Ni}$ asymmetry at $\sim 300 \mathrm{~K}$, the film thickness was 5.5 -9.0 ML. Solid line is a fit as explained in [8].

Fig.3: Average moment of $\mathrm{Co}_{x} \mathrm{Ni}_{1-x} / \mathrm{Cu}(100)$ alloy films using the 'calibration' as explained in the text.

Fig.4: Average moment of $\mathrm{Fe}_{\mathrm{x}} \mathrm{Ni}_{1-\mathrm{x}} / \mathrm{Cu}(100)$ alloy films using the 'calibration' as explained in the text.

Fig.5: Comparison of the calibration curve of fig. 4 and the results of Freeland et al.( points/open squares are for (111)/(100) orientation) [15]. Inluded is also a data point from Keavney et al. (square)[16]. Triangle follows from Kümmerle et al. on $\mathrm{Fe} / \mathrm{Cu}(111)$ [22]. 


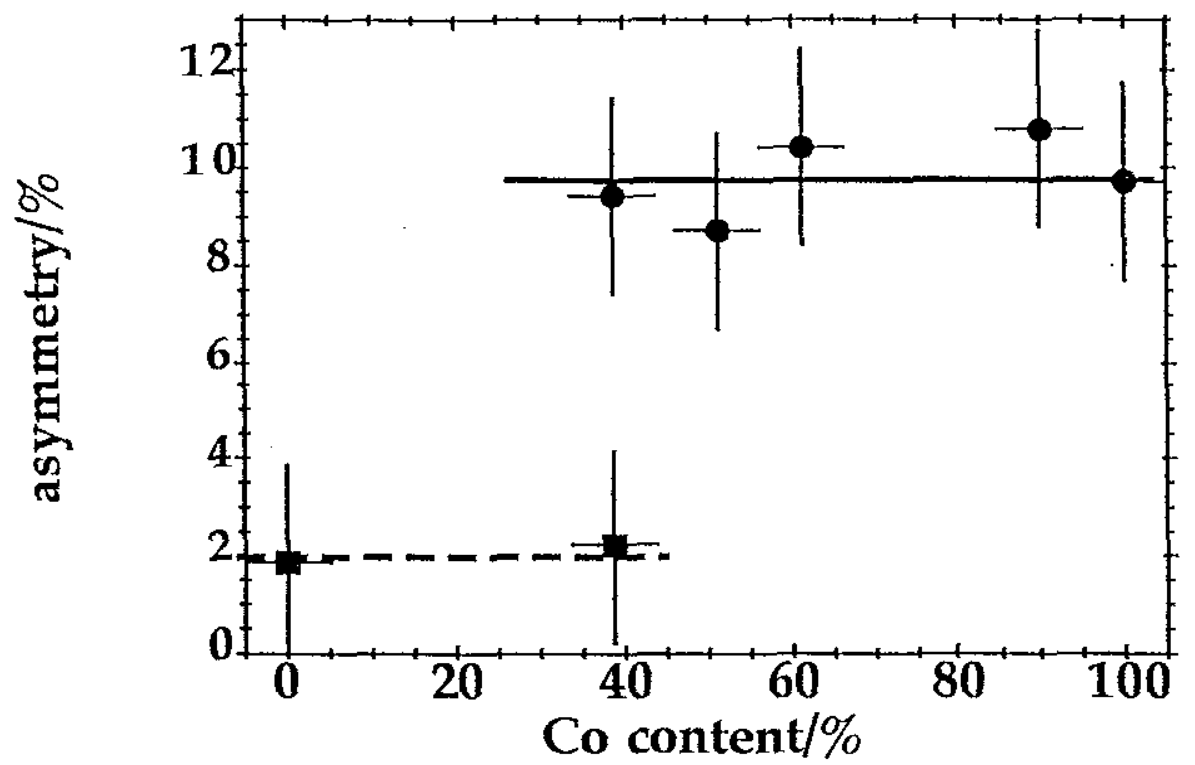

Fig.1

F.O. Schumann et al. 


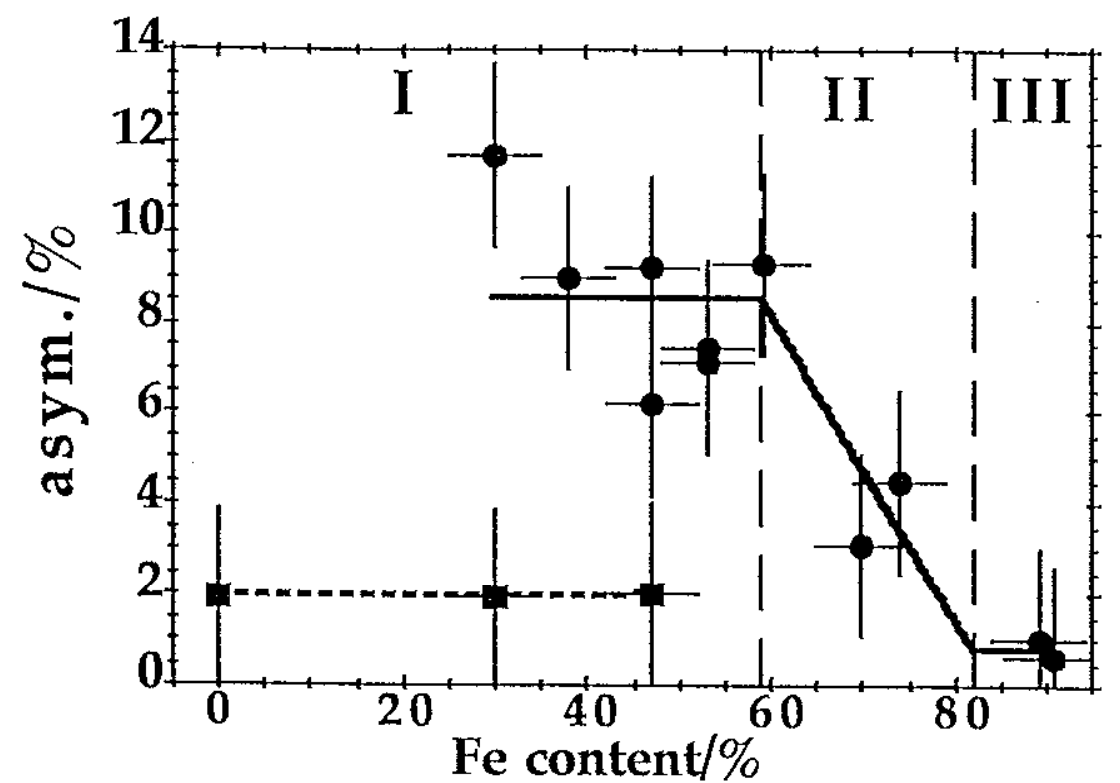

Fig. 2

F.O. Schumann et al. 


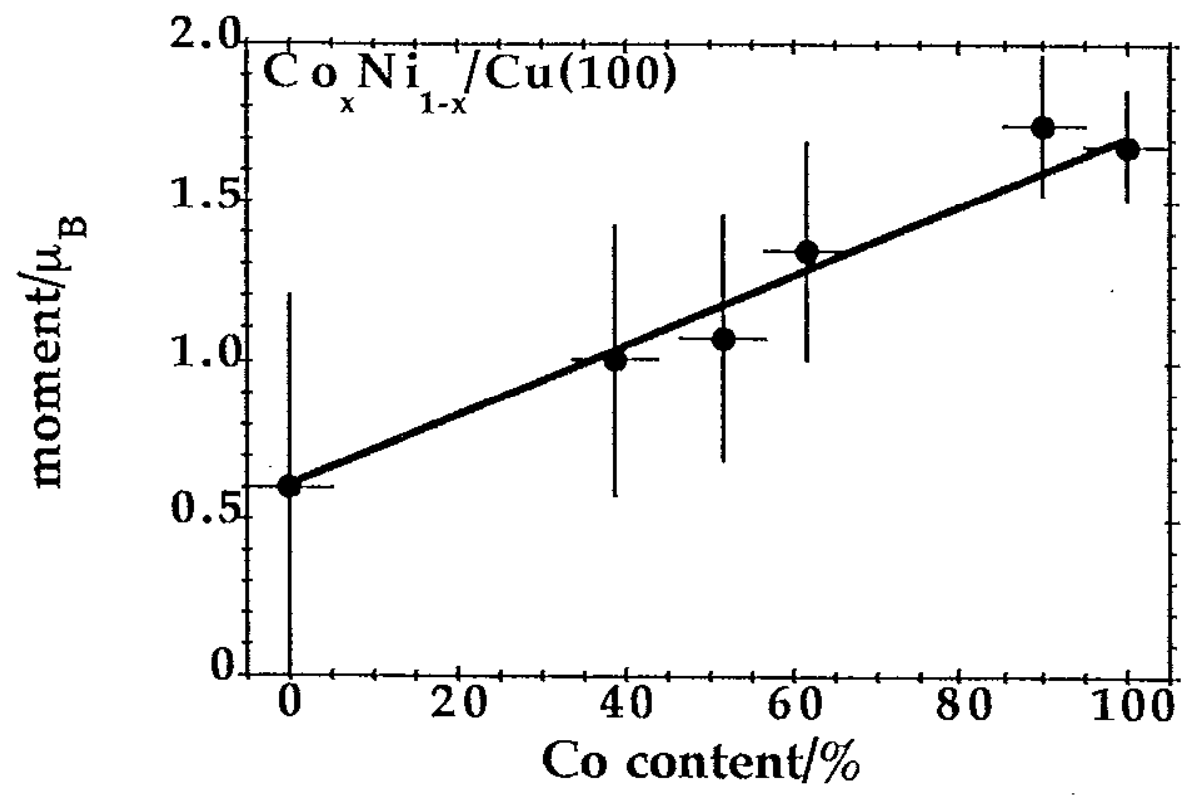

Fig.3

F.O. Schumann et al. 


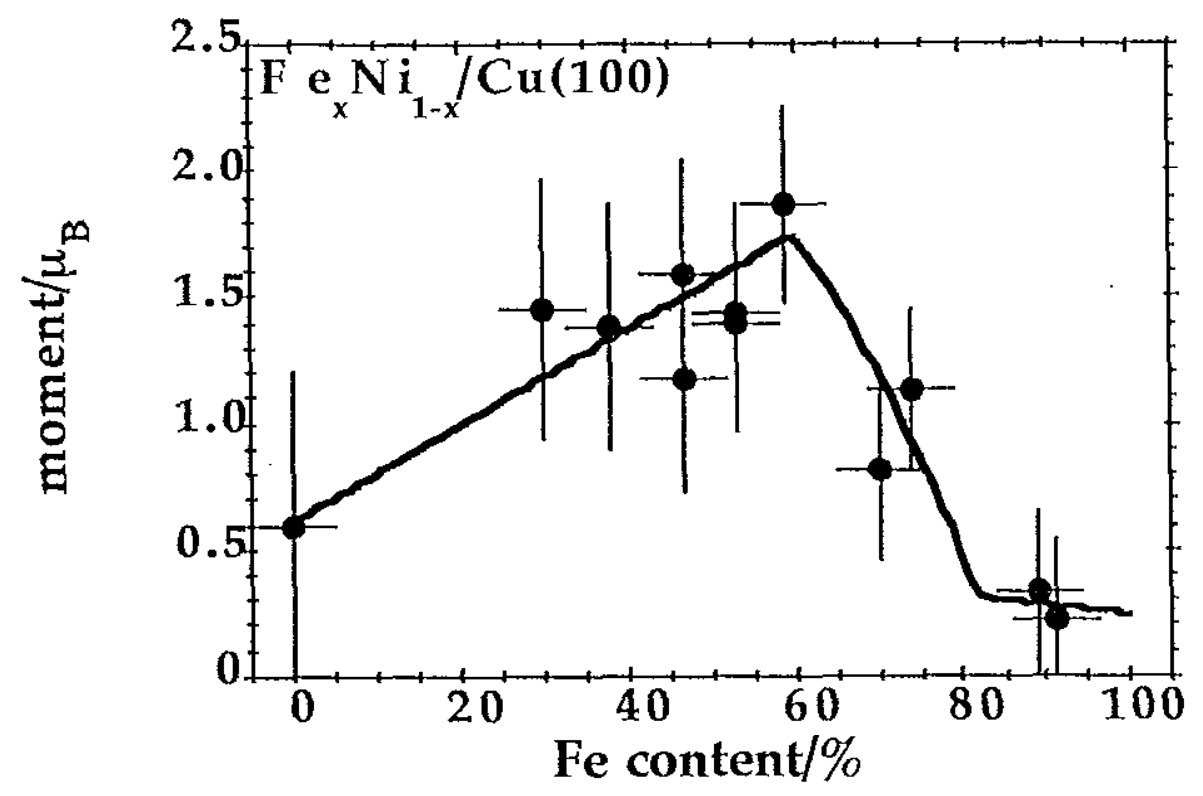

Fig.4

F.O. Schumann et al. 


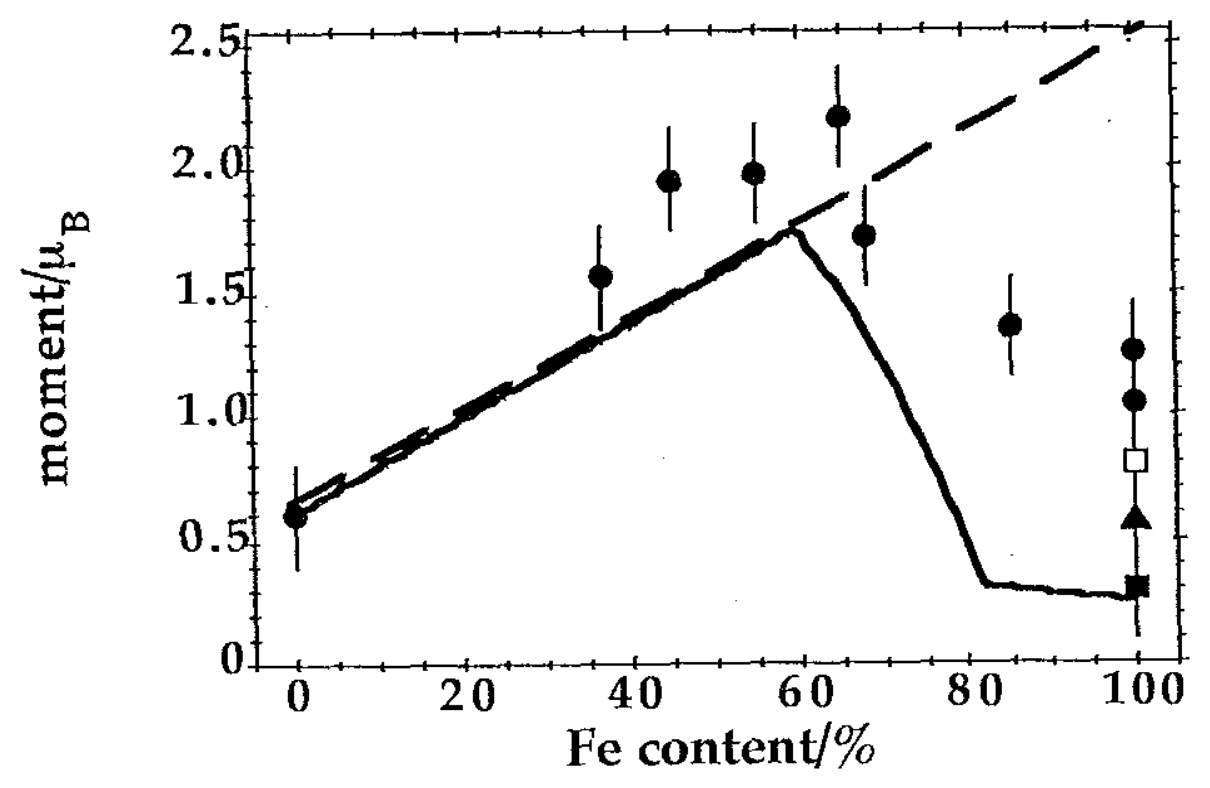

Fig.5

F.O. Schumann et al. 
